\title{
The Impact Of Analysts' Recommendations: Evidence From The Athens Stock Exchange
}

Michalis Glezakos, (Email: migl@ath.forthnet.gr), University of Piraeus, Greece Anna Merika, (Email: merikas@otenet.gr), American College of Greece, Greece

\begin{abstract}
This study aims to investigate the usefulness of analysts' recommendations on firms listed on the Athens Stock Exchange (ASE). It contradicts the majority of published works which conclude that analysts' recommendations do offer valuable investment opportunities. The unique feature of this work is that it sheds light on the issue, adopting a practical approach stemming from the investor's point of view. It is shown through an event study methodology, that analysts' recommendations do not result to any significant excess returns.
\end{abstract}

\section{INTRODUCTION}

n recent years major brokerage houses, spend substantial amounts of resources and time, on fundamental
and technical analysis of listed firms. Moreover, based on this analysis, they attempt to extrapolate and
predict the future, so as to provide their customers with sound advice and contribute towards, improving investors' portfolio returns. It is often the case that this advice assumes the form of analysts' recommendations, which are published through the media (newspapers, and electronic media). The issue under investigation then is, if analysts' recommendations publicly made available, do actually benefit investors by creating significant excess returns.

Academic theory is clearly at odds regarding this issue. More specifically, under the joint hypothesis that a market is efficient and CAPM holds, the only priced factor is systematic risk. Therefore, analysts' recommendations, as well as other kinds of information do not add any value to diversified portfolios. However, a large number of empirical studies have questioned the validity of the above joint hypothesis, depicting that firm size, (Glezakos, M. and Mylonas P.,2003) and historical earnings yield (Glezakos, M.1995), seriously affect stock returns. Regarding the analysts' recommendations, many researchers who tried to investigate the issue seem to agree at least on one aspect, that the financial analysts are capable of pinpointing the undervalued and the overvalued stocks.

Overall, analysts' recommendations take into account a number of parameters, which include real factors related to firm performance as well as market conditions. Therefore, investigating the effectiveness of analysts' recommendations represents a more powerful test of the validity of the semi-strong form of the Efficient Market Hypothesis, than the corresponding traditional tests, which focus solely on corporate events. However, it must be stressed out that an investment strategy, based on analysts' recommendations, would carry with it, a substantial transaction cost. As a result, the net benefit might be zero.

\section{LITERATURE REVIEW}

Investigating the usefulness of analysts' recommendations has been the focus of research interest for many scholars. An overview of their findings suggests that as a general consensus, the analysts deal with the stocks of financially sound firms. Contributing to this is the fact, that during the last 10-15 years, huge funds have been concentrated in the hands of institutional investors, who basically invest in large and profitable companies. That is why, the positive recommendations by analysts are a multiple of the negative ones. An additional factor is that many analysts follow stocks that have attracted the interest of the institutional investors. So they make recommendations when the stock prices are already high enough. In those cases, it is apparent that recommendations have limited value for the investors. 
An extensive literature review on the issue, shed light to the following findings. Positive abnormal returns, due to the analysts' recommendations, were found by Givoly and Lakonishok (1979), Groth et al (1979) and Bjering et al (1983). Also, Holloway (1981 and 1983), concluded that Value Line rankings were valuable, given that rank 1 stocks outperformed the market, even after the deduction of transaction costs. Liu,Smith and Syed(1990), focused on the Wall Street Journal study, and discovered that the information shown under the column 'Heard on the Street' lead to substantial returns of the order of 3.5\% in the month following. By the same token, Barber and Loefler (1993), who analyzed the information under the column 'Dartboard', were able to show excess returns of the order of $4 \%$. Stickel (1995) and Womack (1996), focusing on the changes in the analysts' recommendations, concluded that they do offer profitable investment opportunities.

The Wall Street Journal evaluated the effectiveness of analysts' recommendations, comparing the results with those of a group of stocks selected at random (dartboard portfolio) and also with the Dow Jones. The outcome from this comparative study was that the analysts' perform slightly better, if one does not take into account dividends and investors' risk (Walker and Hatfield, 1996).

Barber, Lehany McNichols and Trueman (2001), utilizing data from Zack's data base, found an excess return of $4 \%$ for stocks which attracted a "strong buy" recommendation. Narashiman et al (2004), deriving data from the same data-base, conclude that only changes in the analysts' recommendations are associated with substantial abnormal returns. On the other hand, Copeland and Myers (1982), utilizing data from Value Line, reached the reverse conclusion. Similarly, Walker and Hatfield (1996), concluded that individual investors experience inferior performance by following analysts' recommendations published in the "Market Highlights" of "USA Today". However, it must be pointed out that most studies with positive results, do not consider transaction costs, which are substantial, mainly because all methodologies which lead to excess returns assume daily rebalancement of the formed portfolios. Overall, the majority of evidence up to date shows that analysts' recommendations lead to abnormal returns, which are not maintained if transaction costs are taken into account. Furthermore, even though analysts can pinpoint overvalued and undervalued shares, it is only for short-term investor horizon.

\section{THE SAMPLE}

This study gathered information from the daily electronic press, where there is free access without any cost or delay. The most widely accessed sites both by brokerage firms as well as investors, were selected. Similar studies, used newspaper information like 'USA Today' and 'Wall Street Journal' in Barber and Loefler (1993), Lieu, Smith and Syed (1993), Holloway (1981 and 1983), Walker and Hatfield (1996) etc. Recent works derived information from 'Zacks Investment Research', which includes a large number of recommendations (over 400,000) since 1985. Unfortunately, for Greece there is no provision of a similar service due to the late development of the stock exchange mainly over the last 7-8 years. In total we've been able to gather 727 recommendations over the period 1/8/2004$31 / 7 / 2005$. Over the chosen period, the General Index experienced a substantial rise of over $30 \%$.Out of the 727 recommendations, 66 were merged because they referred to cases where different analysts recommended the same stock, the same day. So, 661 recommendations are included in the present study, which is a pretty good figure in the context of the relevant literature.

Recommendations for I.P.O.'s were not included, given that investors usually treat them as underpriced, at least in the first trading days (Glezakos and Gotzageorgis,2005). The standard methodology of scholars, when investigating analysts' recommendations is to group them into 5 categories, which cover the whole spectrum from a 'strong buy' recommendation up to a 'strong sell'. More specifically, the five categories are: 1) Strong Buy, 2) Buy, 3)Hold, 4)Sell and 5)Strong Sell. The recommendations we collected, are not classified according to the categories above, instead they specify a target price. For example, the current price of a share is $€ 4,5$ and a $€ 6$ target price is announced. So what we have done, in order to convert to the classification of the literature, is to define deviations from the current price, and classify the deviations accordingly. Therefore, for a $20 \%$ higher target price, from the current, the recommendation is classified as strong buy, group 1. If the deviation is between $10 \%-20 \%$, the recommendation is buy and classified in group 2. Similarly, group 3, contains recommendations with deviations between $0 \%-10 \%$, group 4 contains recommendations with negative deviations between $0 \%-10 \%$ and group 5 contains recommendations with negative deviations greater than $10 \%$. It is not rare that, modifications like the above 
occur. For example, 'Zacks Investment Research', converts the analyst's rating, independently of the scale used, to its five- point scale.

Table 1: Distribution Of Analysts' Recommendations

\begin{tabular}{|c|c|c|c|c|c|c|c|}
\hline \multirow[t]{2}{*}{ Company/ Share } & \multirow{2}{*}{$\begin{array}{c}\text { No. of } \\
\text { Recommendations } \\
\text { per Company }\end{array}$} & \multicolumn{5}{|c|}{$\begin{array}{c}\text { No. of Recommendations per } \\
\text { Category }\end{array}$} & \multirow{2}{*}{$\begin{array}{c}\text { No. of } \\
\text { Brokerage } \\
\text { Houses that } \\
\text { Recommended } \\
\text { the Company }\end{array}$} \\
\hline & & 1 & 2 & 3 & 4 & 5 & \\
\hline $3 \mathrm{E}$ & 28 & 5 & 10 & 11 & 1 & 1 & 15 \\
\hline ALPHA BANK & 32 & 11 & 11 & 9 & 1 & 0 & 12 \\
\hline ATTICA GROUP & 5 & 4 & 1 & 0 & 0 & 0 & 3 \\
\hline AUTOHELLAS & 4 & 4 & 0 & 0 & 0 & 0 & 3 \\
\hline CARDICO & 1 & 1 & 0 & 0 & 0 & 0 & 1 \\
\hline CHIPITA & 2 & 0 & 1 & 1 & 0 & 0 & 2 \\
\hline COSMOTE & 31 & 1 & 17 & 12 & 1 & 0 & 17 \\
\hline CROWN HELLAS & 1 & 1 & 0 & 0 & 0 & 0 & 1 \\
\hline ELMEC & 5 & 3 & 1 & 1 & 0 & 0 & 3 \\
\hline EUROBANK & 24 & 3 & 11 & 7 & 3 & 0 & 11 \\
\hline EUROMEDICA & 1 & 1 & 0 & 0 & 0 & 0 & 1 \\
\hline FOLLI & 26 & 12 & 9 & 5 & 0 & 0 & 9 \\
\hline FOURLIS & 9 & 1 & 5 & 2 & 1 & 0 & 6 \\
\hline FRIGOGLASS & 9 & 6 & 2 & 1 & 0 & 0 & 4 \\
\hline HYATT & 12 & 3 & 5 & 4 & 0 & 0 & 9 \\
\hline IMAKO & 3 & 3 & 0 & 0 & 0 & 0 & 1 \\
\hline INFORM LYKOS & 2 & 1 & 0 & 1 & 0 & 0 & 1 \\
\hline INTRACOM & 7 & 1 & 3 & 3 & 0 & 0 & 5 \\
\hline INTRALOT & 29 & 9 & 2 & 10 & 6 & 2 & 10 \\
\hline JUMBO & 13 & 3 & 8 & 2 & 0 & 0 & 6 \\
\hline GERMANOS & 32 & 6 & 14 & 11 & 1 & 0 & 13 \\
\hline DEH & 32 & 8 & 14 & 8 & 0 & 2 & 14 \\
\hline DELTA SYMETOHON & 1 & 1 & 0 & 0 & 0 & 0 & 1 \\
\hline NATIONAL BANK & 45 & 9 & 27 & 9 & 0 & 0 & 16 \\
\hline HEL. PETROL. & 7 & 0 & 5 & 2 & 0 & 0 & 4 \\
\hline HEL. TEHNOD. & 7 & 7 & 0 & 0 & 0 & 0 & 4 \\
\hline COMMERCIAL BANK. & 11 & 1 & 1 & 3 & 1 & 5 & 7 \\
\hline EHAE & 12 & 0 & 2 & 8 & 2 & 0 & 7 \\
\hline ATHENS ELECTRONIKI & 3 & 3 & 0 & 0 & 0 & 0 & 1 \\
\hline MAILLIS & 20 & 13 & 4 & 2 & 1 & 0 & 9 \\
\hline MAPAK & 2 & 2 & 0 & 0 & 0 & 0 & 1 \\
\hline METKA & 8 & 3 & 4 & 1 & 0 & 0 & 6 \\
\hline MINOIKES & 4 & 2 & 1 & 0 & 1 & 0 & 3 \\
\hline MOHLO & 1 & 1 & 0 & 0 & 0 & 0 & 1 \\
\hline MITILINAIOS & 8 & 7 & 1 & 0 & 0 & 0 & 6 \\
\hline NEOHIMIKI & 1 & 1 & 0 & 0 & 0 & 0 & 1 \\
\hline NIKAS & 2 & 1 & 0 & 1 & 0 & 0 & 1 \\
\hline OPAP & 26 & 1 & 8 & 12 & 5 & 0 & 14 \\
\hline PETZETAKIS & 2 & 2 & 0 & 0 & 0 & 0 & 2 \\
\hline PLAISIO & 8 & 3 & 5 & 0 & 0 & 0 & 5 \\
\hline KAE & 24 & 5 & 12 & 7 & 0 & 0 & 12 \\
\hline KLEEMAN & 4 & 1 & 2 & 1 & 0 & 0 & 3 \\
\hline MOTOR OIL & 15 & 0 & 9 & 6 & 0 & 0 & 6 \\
\hline NOTOS COM & 11 & 11 & 0 & 0 & 0 & 0 & 4 \\
\hline OTE & 48 & 5 & 16 & 18 & 9 & 0 & 16 \\
\hline
\end{tabular}




\begin{tabular}{|c|c|c|c|c|c|c|c|c|}
\hline S \& B & 5 & 4 & 0 & 1 & 0 & 0 & 3 \\
\hline SPRIDER & 2 & 2 & 0 & 0 & 0 & 0 & 2 \\
\hline JP AVAX & 4 & 4 & 0 & 0 & 0 & 0 & 2 \\
\hline AKTOR & 4 & 4 & 0 & 0 & 0 & 0 & 3 \\
\hline ALUMINIO & 3 & 1 & 0 & 0 & 2 & 0 & 3 \\
\hline ROKAS & 1 & 0 & 1 & 0 & 0 & 0 & 1 \\
\hline SARANTIS & 9 & 1 & 4 & 2 & 2 & 0 & 5 \\
\hline TEGOPOULOS & 1 & 0 & 1 & 0 & 0 & 0 & 1 \\
\hline TERNA & 1 & 1 & 0 & 0 & 0 & 0 & 1 \\
\hline TEHNIKI OLYMPIAKI & 3 & 1 & 0 & 2 & 0 & 0 & 2 \\
\hline TILETIPOS & 6 & 0 & 1 & 2 & 2 & 1 & 4 \\
\hline TITAN & 29 & 3 & 12 & 9 & 2 & 3 & \\
\hline ATTIKA BANK & 1 & 0 & 1 & 0 & 0 & 0 & 12 \\
\hline PIRAEUS BANK & 13 & 6 & 0 & 4 & 2 & 1 & 6 \\
\hline HATZIOANNU & $\mathbf{6 6 1}$ & 1 & 0 & 0 & 0 & 0 & \\
\hline $\begin{array}{c}\text { Total No. of } \\
\text { Recommendations }\end{array}$ & $\mathbf{1 9 4}$ & $\mathbf{2 3 1}$ & $\mathbf{1 7 8}$ & $\mathbf{4 3}$ & $\mathbf{1 5}$ & \\
\end{tabular}

As it appears from Table 1, the 661 recommendations refer to 60 firms, a number which is approximately one sixth of the total number of companies listed in the Athens Stock Exchange. It does represent though $75 \%$ of their total market value. Our sample, confirms what is already known from the literature, that financial analysts are mainly interested in large firms, because they meet the criteria and reduce the risk of false prediction.

The analysts' recommendations in our sample came from 28 different brokerage houses, out of which 17 focused on the telecommunications company (COSMOTE), while for OTE, there were 48 recommendations made within the twelve month period under investigation, on average four recommendations a month. It is rather impressive that $91 \%$ of the recommendations were positive and only $9 \%$ were negative. In categories 1 and 5 the percentages were $29.3 \%$ and $2.3 \%$ respectively. Also with respect to some companies, we observe that they have been through the whole spectrum within the period under consideration, from 1 up to 5 . The eagerness of analysts to recommend positively becomes apparent from Table 2, which presents the repetitions of the initial recommendation as well as its variation.

Table 2: Shift Of Analysts' Recommendations

\begin{tabular}{|c|c|c|c|r|c|}
\hline & \multicolumn{5}{|c|}{ To Recommendation of : } \\
\hline From Recommendation of : & $\mathbf{1}$ & $\mathbf{2}$ & $\mathbf{3}$ & $\mathbf{4}$ & $\mathbf{5}$ \\
\hline $\mathbf{1}$ & $15,1 \%$ & $7,6 \%$ & $4,1 \%$ & $1,0 \%$ & $0,3 \%$ \\
\hline $\mathbf{2}$ & $5,9 \%$ & $14,0 \%$ & $12,5 \%$ & $1,1 \%$ & $0,3 \%$ \\
\hline $\mathbf{3}$ & $4,4 \%$ & $10,0 \%$ & $8,2 \%$ & $2,8 \%$ & $2,0 \%$ \\
\hline $\mathbf{4}$ & $0,8 \%$ & $1,6 \%$ & $2,8 \%$ & $2,0 \%$ & $0,2 \%$ \\
\hline & $0,3 \%$ & $0,5 \%$ & $0,5 \%$ & $1,5 \%$ & $0,5 \%$ \\
\hline
\end{tabular}

More specifically, in $39.7 \%$ of the cases the analysts repeated the same recommendation, in $44.5 \%$ they repeated a positive recommendation and in $4.1 \%$ they repeated a negative recommendation. Finally, only $7.6 \%$ of recommendations changed from positive to negative and $6.6 \%$ from negative to positive. The findings above coincide with those of Barber, Lehany, McNichols and Trueman (2001), for NYSE and AMEX and confirm the eagerness of the analysts to recommend positively. 


\section{METHODOLOGY}

We focused on the influence of analysts recommendations on stock returns and employed an event study methodology. After the big stock exchange rise and fall of 1999, the majority of Greek investors, as evidence suggests from the official data of the Stock Market Clearing House, developed a profile with distinct, well defined characteristics. On the basis of these characteristics and through an extensive empirical research over the last six years1,through questionnaires, personal interviews and secondary data kept by the Athens Stock Exchange Statistical Office, the average investor implements an investment strategy as follows:

- Invest in index stocks which are included in analysts' recommendations

- $\quad$ Invests up to $€ 20,000$ (average portfolio value)

- Does not diversify according to the beta coefficient but tend to concentrate on stocks which follow the General Stock Index very closely and are recommended.

- $\quad$ He has short term investment horizon

The above strategy abides by usual practice. It has the significant advantages that does not require very close monitoring or daily rebalancement and therefore avoids the huge costs associated with it. We proceeded by constructing five portfolios according to the five levels of recommendations (strong buy, buy, hold, sell, strong sell) and we then measured the returns of these portfolios. Specifically, to construct the portfolios the following steps were followed.

(i) We classified the 661 recommendations into the five categories as stated above.

(ii) We constructed the five portfolios 1-5, according to recommendations in the following way.

- The sample recommendations were classified in daily chronological order during the period under examination.

- In cases that different analysts recommended the same stock, the same day, but different target prices, we calculated the average target price price, which is the usual practice in the literature (Barber et.al (2001) and Jegadeesh et. al (2004)).

- $\quad$ Each stock remained in the initial portfolio until it was reclassified to another category by analysts

(iii) The returns of the five portfolios were measured for the following periods compared to the day that securities were included in the initial portfolio.

- $\quad$ For the next day $(\mathrm{t}+1)$

- $\quad$ For next week $(t+1, t+5)$

- $\quad$ For the previous day (t-1) and for the period $(\mathrm{t}-1, \mathrm{t})$ aiming to discover if the market has been informed

- $\quad$ For the next month $(\mathrm{t}+1, \mathrm{t}+21)$.

To be able to get meaningful results, it is required that the structure of the portfolios remains relatively stable. To accomplish this, we change the structure of our portfolios only in the case that a recommendation changes from positive to negative.

More specifically, in order to overcome the problem, we assumed (especially for the measurement of monthly returns), that the investors do not drop a stock when an inferior recommendation is published, except in the case that it changes from class 1-3 to class 4-5 and vice versa. 
(iv) The return of each stock over a specific period $\left(\mathrm{R}_{\mathrm{it}}\right)$ was calculated by he formula

$R_{i t}=\frac{P_{i t}-P_{i, t-1}}{P_{i, t-1}}$

Where $\mathrm{P}_{\mathrm{i}, \mathrm{t}-1}$ and $\mathrm{P}_{\mathrm{it}}$ are the stock prices at the beginning and the end of the period respectively (dividends are not included). In cases that the number of stocks of a company changed within the period under examination, (i.e. split, reverse split), the prices $\mathrm{P}_{\mathrm{i}, t-1}$ were modified according to the coefficient $\sigma$, given by the relationship below while the stock returns were calculated by formula (3) below.

$$
\sigma=\frac{N\left(P_{t-1}\right)+n P n}{(N+n)\left(P_{t-1}\right)}
$$

Where $\mathrm{N}=$ no. of stocks before the change in the capital structure of the company, $\mathrm{n}=$ the no. of new stocks and $\mathrm{Pn}=$ the market price of the new stocks.

$R_{i t}=\frac{P_{i t}-\sigma P_{i, t-1}}{\sigma P_{i, t-1}}$

(v) The portfolio return was calculated under the assumption of equally weighted stock returns

$$
R p t=\left(\sum_{i=1}^{N} R_{i}\right) / N
$$

(vi) From the respective portfolio returns we deducted the Athens Stock Index, over the corresponding period.

(vii) The coefficient of systematic risk, b, for each of the 60 stocks in our sample was estimated over the period $31 / 7 / 2002$ up to 30/7/2004,497 observations in total, on the basis of the market model. The OLS method of estimation gave biased standard errors for the estimated coefficients due to the breaking down of the property of heteroskedasticity. Next, the model was tested for ARCH and GARCH effects and we finally ended up estimating by Maximun Likelihood the following model GARCH(1,1) for the 60 firms.

$\mathrm{R}_{\mathrm{it}}=\mathrm{a}_{\mathrm{i}}+\mathrm{b}_{\mathrm{i}} \mathrm{R}_{\mathrm{mt}}+\mathrm{u}_{\mathrm{t}}$

And $\quad \mathrm{h}_{\mathrm{t}}=\gamma+\delta \mathrm{u}_{\mathrm{t}-1}^{2}+\kappa \mathrm{h}_{\mathrm{t}-1}$

Where $R_{m t}$ is the market return at time period $t$ and $a_{i}$ the estimated market model intercept. The variance of the residuals, $h_{t}$, is then regressed on the lagged value of the residual $u_{t}$ and the lagged value of itself.

Each portfolio systematic risk was calculated by the the formula below.

$$
b_{p}=\left(\sum_{i=1}^{N} b_{i}\right) / N
$$


Analyzing the results from Table 3, it is suggested clearly that investors' decisions should be affected by the published recommendations.

Table 3: Raw Returns Of The Formed Portfolios

\begin{tabular}{|c|c|c|c|c|c|}
\hline & Portfolio 1 & Portfolio 2 & Portfolio 3 & Portfolio 4 & Portfolio 5 \\
\hline$t+1$ & $0,63 \%$ & $0,27 \%$ & $0,17 \%$ & $-0,24 \%$ & $-0,91 \%$ \\
\hline$t+1, t+5$ & $0,97 \%$ & $0,51 \%$ & $0,71 \%$ & $0,30 \%$ & $-1,3 \%$ \\
\hline$t-1, t$ & $0,08 \%$ & $0,53 \%$ & $0,6 \%$ & $1,36 \%$ & $0,77 \%$ \\
\hline
\end{tabular}

More particularly, in the first day after the publication of a recommendation, the prices of the strongly suggested shares rise by $0,63 \%$ while they fall by $0,91 \%$ for those stocks which received the worst recommendations. Moreover, the relationship between the level of recommendation and the corresponding returns is almost linear. The above conclusions don't change when index-adjusted returns are considered.

Table 4: Index Adjusted Returns Of The Formed Portfolios

\begin{tabular}{|c|c|c|c|c|c|}
\hline & Portfolio 1 & Portfolio 2 & Portfolio 3 & Portfolio 4 & Portfolio 5 \\
\hline$t+1$ & $0,36 \%$ & $0,06 \%$ & $0,08 \%$ & $-0,91 \%$ & $-0,97 \%$ \\
\hline$t+1, t+5$ & $0,35 \%$ & $-0,12 \%$ & $0,38 \%$ & $-1,3 \%$ & $-1,34 \%$ \\
\hline$t-1, t$ & $-0,19 \%$ & $0,17 \%$ & $0,29 \%$ & $0,77 \%$ & $0,02 \%$ \\
\hline
\end{tabular}

Looking at the previous day returns of the day that recommendations are published $(\mathrm{t}-1, \mathrm{t})$, it appears that portfolios 4 and 5 are superior. One could therefore argue that, analysts' recommendations influence investors so much that their preferences can be reversed within the day. It is also clear from our findings that recommendations do not become known before they are published. That is why there is a reversal in investors' preferences a day after recommendations are published. How long does the influence last for? From the tables3-5 it appears that the stocks with positive recommendations perform better compared to those stocks with negative recommendations, $(0.73 \%$ against $-0.50 \%)$.

Table 5: Returns Of The Positive And Negative Portfolios

\begin{tabular}{|c|c|c|c|c|}
\hline & \multicolumn{2}{|c|}{ Raw returns } & \multicolumn{2}{c|}{ Index Adjusted Returns } \\
\hline & Portfolios 1-3 & Portfolios 4-5 & Portfolios 1-3 & Portfolios 4-5 \\
\hline$t+1$ & $0,36 \%$ & $-0,58 \%$ & $0,17 \%$ & $-0,94 \%$ \\
\hline$t+1, t+5$ & $0,73 \%$ & $-0,50 \%$ & $0,20 \%$ & $-1,32 \%$ \\
\hline$t-1, t$ & $0,40 \%$ & $1,07 \%$ & $0,09 \%$ & $0,40 \%$ \\
\hline$t+1, t+21$ & $3,10 \%$ & $2,72 \%$ & $-0,04 \%$ & $0,37 \%$ \\
\hline
\end{tabular}

The difference among the two categories remains strong in terms of the modified returns as well $(0.20 \%$ against $-1.32 \%)$. In any case a month after, the recommendations influence has disappeared $(3.1 \%$ against $2.72 \%)$. If the modified returns are taken into account the picture is reversed: The portfolio that includes the stocks with positive recommendations has a negative overall return $0.045 \%$ while the portfolio with the negatively recommended stocks has a positive return of $0.37 \%$. This implies that over a holding period of one month, there is no benefit out of analysts' recommendations. On the contrary, these are useful for weekly stock transactions. If one though takes into account transaction costs, it severely limits or outweighs the benefits. Especially for private investors the transaction cost varies between 1.15-1.50\%. The excess returns therefore that appear in tables 4 and 5 are not sufficient to cover 
transaction costs. (This is in line with Barber et al (2001) for the NYSE and the AMEX).

In theory, one could achieve a positive return buying stocks of portfolio 1 and selling stocks of portfolio 5(short selling). In practice though this is not feasible, because short selling is not allowed with all stocks and furthermore the liquidity offered by the Athens Derivatives Exchange for such transactions, is limited. It must be pointed out that the calculation of the excess returns of the portfolios assumes implicitly, that the systematic risk of the formed portfolios is equal to 1 . If this is not the case then the above prices have no meaning. From Table 6, it appears that the systematic risk of the five portfolios is close to one, therefore false interpretation of the returns is ruled out.

Table 6: Systematic Risk Estimations For The Formed Portfolios

\begin{tabular}{|l|l|}
\hline & beta \\
\hline $\mathbf{1}$ & 1,06 \\
\hline $\mathbf{2}$ & 0,96 \\
\hline $\mathbf{3}$ & 0,93 \\
\hline $\mathbf{4}$ & 0,99 \\
\hline $\mathbf{5}$ & 0,97 \\
\hline
\end{tabular}

Like Barber et al (2001), we examined the influence of the degree of coverage of stocks by the analysts in the following manner. We constructed portfolios of 'widespread coverage' comprised of stocks that have attracted the interest of the analysts (i.e. over half of the analysts recommended them a few times). We constructed portfolios of 'neglected coverage' comprised of stocks that only one analyst has recommended once. We then compare the returns of the above portfolios. If the differences are substantial then it can be attributed to the amount of coverage received by the stocks. It appears from Table 7 that, when recommendations are positive, investors are not influenced by the amount of coverage received by the stocks.

Table 7: Returns Of The Higly Covered And Neglected Stocks-Criterion: Number Of The Analysts Per Share

\begin{tabular}{|c|c|c|c|c|}
\hline & \multicolumn{2}{|c|}{ Highly Covered } & \multicolumn{2}{c|}{ Neglected } \\
\hline & $\begin{array}{c}\text { Positive } \\
\text { Recommendations }\end{array}$ & $\begin{array}{c}\text { Negative } \\
\text { Recommendations }\end{array}$ & $\begin{array}{c}\text { Positive } \\
\text { Recommendations }\end{array}$ & $\begin{array}{c}\text { Negative } \\
\text { Recommendations }\end{array}$ \\
\hline $\mathrm{t}+1$ & $0,46 \%$ & $0,49 \%$ & $0,38 \%$ & $-0,22 \%$ \\
\hline $\mathrm{t}+1, \mathrm{t}+5$ & $1,05 \%$ & $1,05 \%$ & $1,08 \%$ & $0,82 \%$ \\
\hline $\mathrm{t}-1, \mathrm{t}$ & $0,39 \%$ & $1,01 \%$ & $0,12 \%$ & $0,42 \%$ \\
\hline
\end{tabular}

On the other hand, if recommendations are negative, they prefer those stocks with widespread coverage. Overall, the degree of coverage influence is practically negligible during the first day as well as the first week. The influence of the degree of coverage was reexamined taking as criterion this time the number of published recommendations per stock.

Table 8: Returns Of The Higly Covered And Neglected Stocks Criterion; Number Of Published Recommendations Per Share

\begin{tabular}{|c|c|c|c|c|}
\hline & \multicolumn{2}{|c|}{ Highly Recommended } & \multicolumn{2}{c|}{ Neglected } \\
\hline & $\begin{array}{c}\text { Positive } \\
\text { Recommendations }\end{array}$ & $\begin{array}{c}\text { Negative } \\
\text { Recommendations }\end{array}$ & $\begin{array}{c}\text { Positive } \\
\text { Recommendations }\end{array}$ & $\begin{array}{c}\text { Negative } \\
\text { Recommendations }\end{array}$ \\
\hline $\mathrm{t}+1$ & $0,36 \%$ & $0,1 \%$ & $1,12 \%$ & Zero observations \\
\hline $\mathrm{t}+1, \mathrm{t}+5$ & $1,3 \%$ & $0,89 \%$ & $1,13 \%$ & Zero observations \\
\hline $\mathrm{t}-1, \mathrm{t}$ & $0,25 \%$ & $0,48 \%$ & $0,75 \%$ & Zero observations \\
\hline
\end{tabular}


More specifically, a portfolio was constructed with the 10 stocks that gathered $50 \%$ of the total number of recommendations and another with stocks that had only one recommendation published. The results appear in Table 8 and show that the number of recommendations has no influence whatsoever, on investors. More specifically, while during the first day after the publication of a recommendation, the neglected stocks have a superior performance, the profit is waved out within the first week. This can be interpreted by investors' behavior. They invest in neglected stocks after analysts recommendations but then liquidate, by the end of the first week in order to invest in well known stocks.

\section{CONCLUSION}

The Greek stock exchange operates in the context of a globalized financial environment and however small an economy it represents, the ASE, is a microcosm of the conflict between market forces and individual investor attitudes in the light of complete information sets, shaped through the provision of the financial press. In the present study it is shown that the financial press does affect the financial markets and may influence investor behavior in a number of ways. Investors for example learn to critically evaluate the firms in which they invest. Also they learn to invest in the best companies since analysts deal with the best of them, which accounts for the fact that the majority of analysts' recommendations are positive.

In the context of a chosen investment strategy, the Greek investor even though the first day after the recommendation seems to be able to make abnormal returns, by the end of the week and even so more, by the end of the 21-day period under consideration, finds his excess return swept away by the substantial transaction costs involved. Our results support the overall conclusion that analysts' recommendations do not offer net excess returns to private investors with reference to the Athens Stock Exchange. It adds another case in support of the efficient market hypothesis.

\section{SUGGESTIONS FOR FUTURE RESEARCH}

A useful extension of this study would be to look at the effect that changes in analysts' recommendations might have on investors' returns. Furthermore, one could look more closely at the formation of the target price by the analysts. It would be interesting to assess whether the evaluation methods used have any impact on target price formation and therefore category or change of recommendation.

\section{ENDNOTES}

1. The authors would like to express their gratitude to P.Kiousoglou for processing the bulk of the data work.

\section{REFERENCES}

1. Barber, B. M. and Loefler, D. (1993), The Dartboard Column: Second Hand Information and Price Pressure, Journal of Financial and Quantitative Analysis, June, pp. 273-284.

2. Barber, B. M., Lehany, R., McNichols, M., and Trueman, B., Can investors Profit from Prophets? Security Analyst Recommendations and Stock Returns, The Journal of Finance, April, 2001, pp.531-565.

3. Bjering, J., Lakonishok J., and Vemaelen, T., Stock Prices and Financial Analysts Recommendations, Journal of Finance, Vol. 38, pp. 187-204, 1983.

4. Copeland, T. E. and Myers, D.,The Value Line Enigma (1965-1978) : A Case Study of Performance Evaluation Issues, Journal of financial Economics, June, pp. 289-322, 1982.

5. Givoly, D. and Lakonishok, J.,The Information Content of Financial Analysts Forecast of Earnings, Journal of Accounting and Economics, Dec., pp. 165-185, 1979.

6. Glezakos, M. and Mylonas P., The Small Size Effect is Still Present on the Athens Stock Exchange, European Research Studies Vol. 6 - Issue 3-4 / 2003.

7. Glezakos, M., The Effect of Accounting Profitability on stock Returns - The Case of the ASE," SPOUDAI, 1995.

8. Glezakos, M. and Gotzageorgis, G., An empirical Investigation of Underpricing in Greek I.P.O.s, 1990-2003, 
European Research Studies , 2005.

9. Groth, J. C., Lewellen, W. G., .Schlarbaum G.G., and Lease R.C., Analysis of Brokerage House Security Recommendations, Financial Analysts Journal, An-Febr, pp. 711-719, 1979.

10. Holloway, C, A Note on Testing an Aggressive Investment Strategy, Using Value Line Ranks, Journal of Finance, pp. 711-719, 1981.

11. Holloway, C., Testing an Aggressive Investment Strategy, Using Value Line Ranks : A Reply, Journal of Finance, pp. 263-270, 1983.

12. Jegadeesh N., Kim J., Krische S., and Lee Ch., Analyzing the Analysts: When Do Recommendations Add Value?, The Journal of Finance, June, pp.1083-1122, 2004.

13. Johnson,J.L. and Ellstrand,A.E., et.al, The Influence of the Financial Press on Stockholder Wealth: The Case of Corporate Governance, Strategic Management Journal, 26:461-471, 2005.

14. Liu, Smith and Syed, Stock Price Reactions to the Wall Street Journal's Security Recommendations, Journal of Financial and Quantitative Analysis, Sept., pp. 399-410, 1990.

15. Peterson PP, Event Studies: A Review of Issues and Methodology, Quarterly Journal of_Business and Economics_28: 36-66, 1989.

16. Stickel, S.E., Common Stock Returns Surrounding Earnings Forecast Revisions : More Puzzling Evidence, The Accounting Review, Vol. 66, pp. 402-416, 1995.

17. Walker, M. M. and Hatfield, G. B., Professional Stock Analysts' Recommendations: Implications for Individual Investors, Financial Services Review, Vol. 5, pp 13-29, 1996.

18. Womack, K., Do Brokerage Analysts' Recommendations Have Investment Value?, Journal of Finance, Vol. 51, pp. 137-167, 1996.

\section{NOTES}

